\title{
Lecythidaceae endémicas del Perú
}

Blanca León ${ }^{1,2}$

${ }^{1}$ Museo de Historia Natural, Av. Arenales 1256, Aptdo. 14-0434, Lima 14, Perú

2 Plant Resources Center, University of Texas at Austin, Austin TX 78712 EE.UU.

blanca.leon@mail.utexas.edu

\section{Resumen}

La familia Lecythidaceae es reconocida en el Perú por presentar ocho géneros y 20 especies (Brako \& Zarucchi, 1993; Ulloa Ulloa et al., 2004), todas ellas árboles. En este trabajo reconocemos dos especies endémicas en dos géneros. Estos taxones endémicos ocupan la región Bosques Húmedos Amazónicos, entre los 100 y 270 m de altitud. Una especie endemica de Lecythidaceae se encuentra representada dentro del Sistema Nacional de Áreas Naturales Protegidas por el Estado.

Palabras claves: Lecythidaceae, Perú, endemismo, plantas endémicas.

\section{Abstract}

Lecythidaceae are represented in Peru by eight genera and 20 species (Brako \& Zarucchi, 1993; Ulloa Ulloa et al., 2004), all of them trees. Here we recognize two endemic species in two genera. These endemic taxa grow in the Humid Lowland Amazonian Forest region, between 100 and $270 \mathrm{~m}$ elevation. One endemic species of Lecythidaceae has been registered in the Peruvian protected areas system.

Keywords: Lecythidaceae, Peru, endemism, endemic plants.

\section{Eschweilera klugii R. Knuth}

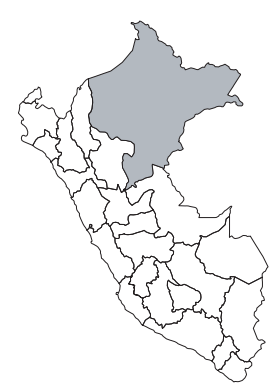

\section{CR, B1ab(iii)}

Publicación: Pflanzenr. IV, 219a (Heft 105): 110. 1939.

Colección tipo: G. Klug 597

Herbarios: NY.

Nombre común: Desconocido.

Registro departamental: LO.

Regiones Ecológicas: BHA; $100 \mathrm{~m}$.

SINANPE: Sin registro.

Herbarios peruanos: Ninguno.

Observaciones: Árbol, conocido solamente de la colección tipo recolectada a fines de la década de 1920. Aparentemente no ha vuelto a ser recolectada, lo que es causa de preocupación, puesto que las áreas boscosas en los alrededores de Iquitos están deterioradas por la deforestación.

\section{Gustavia inakuama S.A. Mori}

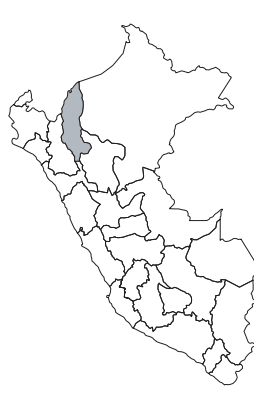

LC

Publicación: Fl. Neotrop. 21(1): 184, f. 54-55. 1979.

Colección tipo: B. Berlin 761

Herbarios: MO.

Nombre común: Sachapapa, sachamango. Registro departamental: AM.

Regiones Ecológicas: BHA; $180-270 \mathrm{~m}$. SINANPE: ZRSC

Herbarios peruanos: USM (1).

Observaciones: Árbol o arbusto, conocido de las cuencas del Cenepa y el Santiago. Numerosos ejemplares de herbario, recolectados durante las décadas de 1970 y 1980, documentan la presencia de esta especie, pero la mayoría no se encuentra en los herbarios peruanos. 